\title{
Self limiting neonatal primary hyperparathyroidism associated with familial hypocalciuric hypercalcaemia
}

\author{
$\mathrm{H}$ Wilkinson, J James
}

\begin{abstract}
A boy is described who presented aged 7 weeks with severe biochemical and radiological neonatal hyperparathyroidism that had completely resolved by the age of 6 months. His mother had a normal serum calcium concentration but his father, paternal aunt, and paternal cousin all had a raised serum calcium due to familial hypocalciuric hypercalcaemia.

(Arch Dis Child 1993; 69: 319-321)
\end{abstract}

Severe neonatal hypercalcaemia due to neonatal hyperparathyroidism can be life threatening. Rarely it can be seen in association with familial hypocalciuric hypercalcaemia, and parathyroidectomy is essential and life saving. ${ }^{1}$ Less severe cases associated with a moderate hypercalcaemia but with extensive metabolic bone disease, however, may resolve spontaneously and can be managed medically, with complete resolution of the bone disease by 7 months of age. ${ }^{23}$

Department, York

District Hospital

Wigginton Road, York

YO3 7 HE

$\mathrm{H}$ Wilkinson

Department of

Paediatrics, Friarage

Hospital,

Northallerton, North

Yorkshire

J James

Correspondence to:

Dr Wilkinson.

Accepted 7 June 1993
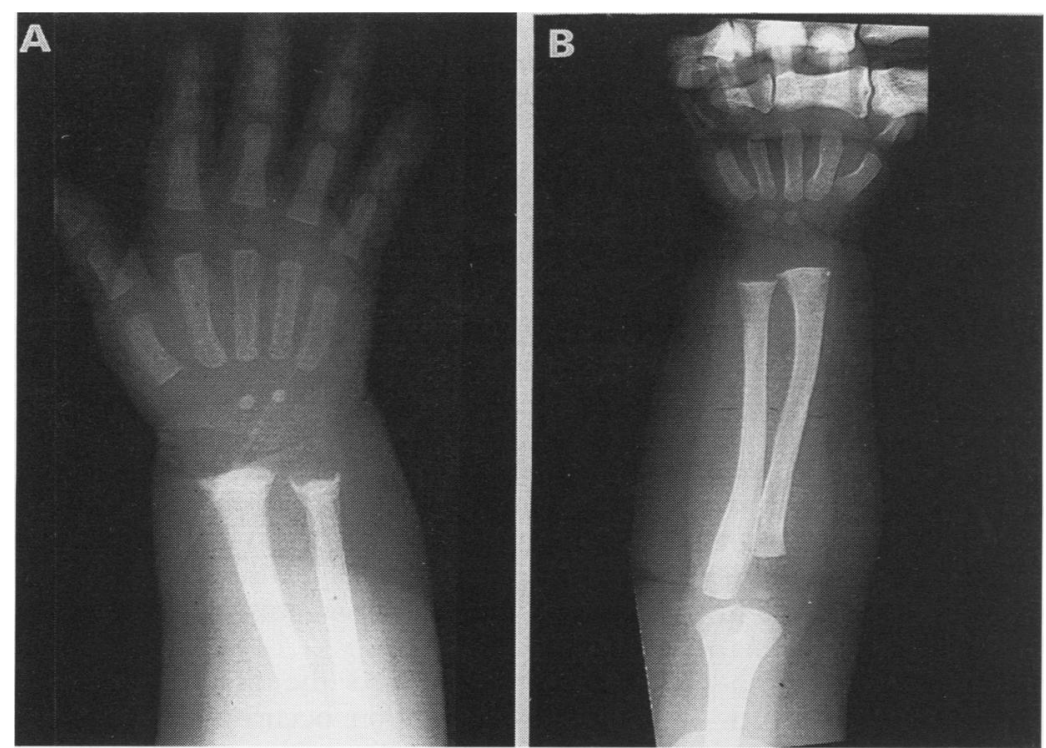

Figure 1 Radiographs of the forearm of the patient. (A) Aged 3 months to show metaphyseal deformity including 'champagne cup' at lower end of ulna. (B) Aged 6 months to show complete healing of metaphyseal deformities. was rather floppy, and had a large liver and spleen. He seemed lethargic and was a poor feeder. He developed a tachypnoea due to chest infection and was started on antibiotics. He then began to feed better and became more lively and went home on day 6 .

On day 17 he was readmitted severely ill with a chest infection and poor feeding. He was noted to have an odd shaped chest with indrawing of the intercostal muscles. His liver and spleen were both enlarged. Shortly after admission he suffered a respiratory arrest, was intubated, and ventilated for two hours. He was started on intravenous antibiotics and made a good recovery. A sweat test was normal.

On day 27 he was readmitted with facial cyanosis and a further apnoeic attack. This recurred on day 31 and he was issued with an apnoea alarm. On examination he appeared to have a distended abdomen otherwise he seemed to be developing normally. Amino acid concentration in the urine and serum immunoglobulins were normal for his age. Abdominal ultrasound was unhelpful.

He suffered repeated apnoeic attacks, chest infections, and vacant episodes over the next four weeks. At this time a review of his notes showed that at 3 weeks of age his serum alkaline phosphatase activity had been $662 \mathrm{U} / 1$. This was repeated at 8 weeks and found to be $1500 \mathrm{U} / 1$. A chest radiograph showed generalised osteopenia with enlarged costochondral junctions and subperiosteal erosions. Radiography of the forearm showed widening and irregularity of the ulnar metaphyses and subperiosteal bone resorption along the diaphyses of both radius and ulna (fig 1A). Physical examination showed craniotabes. His serum calcium concentration adjusted for albumin measured $2.73 \mathrm{mmol} / \mathrm{l}$ (normal range $2 \cdot 1-2 \cdot 6$ ) and serum phosphate $0.96 \mathrm{mmol} / \mathrm{l}$ $(1 \cdot 4-2 \cdot 4)$. Serum ionised calcium was 1.6 $\mathrm{mmol} / \mathrm{l}(1 \cdot 18-1 \cdot 34)$. A random urine calcium: creatinine ratio measured $0.96(0.08-0.74)$, and serum creatinine was $37 \mu \mathrm{mol} / \mathrm{l}$. Radiography and ultrasound of the kidneys showed no evidence of nephrocalcinosis. Serum intact parathyroid hormone (PTH) was $115 \mathrm{pmol} / 1$ (up to $6.0 \mathrm{pmol} / 1$ with a normal serum calcium). Primary hyperparathyroidism was diagnosed. Serum alkaline phosphatase at 11 weeks measured $1330 \mathrm{U} / 1$ and was all of bone origin. Serum magnesium was 0.87 $\mathrm{mmol} / \mathrm{l}(0 \cdot 7-1 \cdot 1)$.

A differential diagnosis between neonatal primary hyperparathyroidism and familial hypocalciuric hypercalcaemia presenting as 


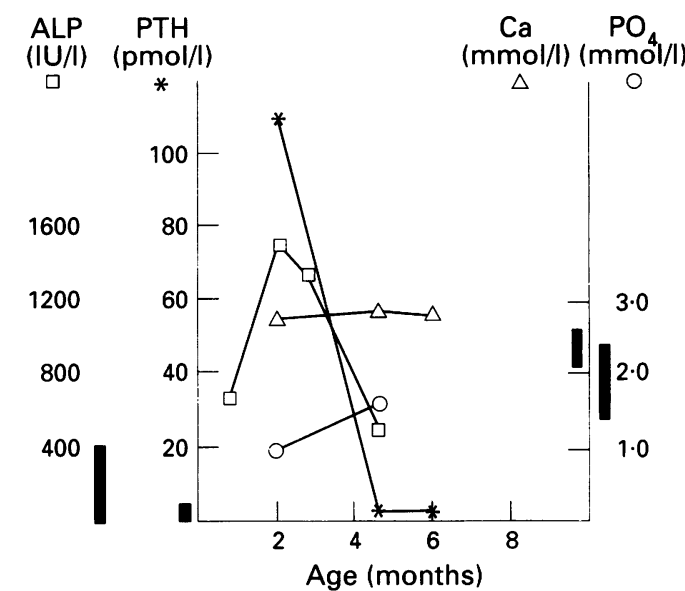

Figure 2 Plot of serum alkaline phosphatase $(A L P)$, albumin adjusted calcium $(\mathrm{Ca})$, phosphate $\left(\mathrm{PO}_{4}\right)$, and intact PTH concentrations against age; bars show normal ranges.

neonatal hyperparathyroidism was made and the baby was transferred to Oxford for further assessment, investigation, and management.

His mother had a normal serum calcium concentration but his father was found to have a raised serum calcium of $2.95 \mathrm{mmol} / \mathrm{l}$. He had a normal serum intact PTH and a low urine calcium concentration of $1.5 \mathrm{mmol} / 24$ hours $(2 \cdot 5-7 \cdot 5)$. The patient's serum intact PTH at 15 weeks was in the normal range and his urine calcium:creatinine ratio had fallen to $0 \cdot 13$.

At 18 weeks the patient's serum alkaline phosphatase was $496 \mathrm{U} / 1$ and his serum intact PTH was $3.2 \mathrm{pmol} / \mathrm{l}$, serum calcium 2.85 $\mathrm{mmol} / \mathrm{l}$, and serum phosphate $1.58 \mathrm{mmol} / \mathrm{l}$ (fig 2). He still suffered apnoeic attacks and vacant episodes. An electroencephalogram was normal. On physical examination his craniotabes had resolved. It was noted that his proximal muscles were hypotonic and this was impeding his motor development. At 6 months radiography of the forearm showed complete healing of the metaphyseal deformities (fig 1B). He continued to suffer apnoeic attacks, chest infections, and have vacant episodes but at 17 months is walking, talking, and developing normally. Further family studies were conducted using blood and urine samples. It was found that the paternal aunt (serum calcium $2.96 \mathrm{mmol} / \mathrm{l}$, intact PTH $4.9 \mathrm{pmol} / \mathrm{l}$, urine calcium $2 \cdot 12 \mathrm{mmol} / 24$ hours) and a paternal cousin (serum calcium $2.98 \mathrm{mmol} / \mathrm{l}$, intact PTH $4.4 \mathrm{pmol} / \mathrm{l}$, urine calcium 0.4 $\mathrm{mmol} / 24$ hours) also had familial hypocalciuric hypercalcaemia.

\section{Discussion}

Familial hypocalciuric hypercalcaemia was first described by Foley et al in $1972 .{ }^{4}$ It has an autosomal dominant mode of inheritance with high penetrance. Its exact incidence is unknown, but is variously estimated at one in $200^{5}$ to one in $20^{6}$ cases of hypercalcaemia. The characteristics of the disease are: symptomless hypercalcaemia, normal PTH concentrations, reduced calcium concentrations in the urine in most cases, ${ }^{4-6}$ and family studies complete the diagnosis.
In 1982 Marx et al described four cases of severe neonatal hyperparathyroidism in three kindreds with familial hypocalciuric hypercalcaemia. ${ }^{1}$ The four babies presented at birth and had serum calcium concentrations between 3.47 and $6.0 \mathrm{mmol} / \mathrm{l}$. Their PTH concentrations were five times the upper limit of normal. All suffered the typical features of hypercalcaemia, muscular hypotonia and skeletal undermineralisation, and all had total parathyroidectomies. The glands were hyperplastic but no adenomas were found. Two babies died of respiratory insufficiency.

It is unknown why a few babies born into families with familial hypocalciuric hypercalcaemia should have severe hyperparathyroidism while most are symptom free and remain so until identified quite incidentally in later life. It can be said that neonatal hyperparathyroidism represents one end of a spectrum of unexplained variation in the clinical severity of familial hypocalciuric hypercalcaemia. It is suggested that the parathyroid glands of affected subjects are less than usually sensitive to the ionised calcium in the blood, so that a higher concentration of calcium is required to 'switch off' PTH production. 4 Calcium is actively transported across the placenta in the maternofetal direction resulting in a higher concentration of plasma calcium in the fetus than in the mother in the second half of pregnancy. It follows that an unaffected mother with a normal serum calcium would be exposing an affected fetus to a relatively hypocalcaemic environment. Once the fetal parathyroids begin to develop at 20 weeks they would then overdevelop to adjust the serum calcium to a higher setpoint and the fetus develops hyperparathyroidism. As seen in our patient, after delivery the hyperparathyroidism gradually remits and the metabolic bone disease heals (fig 1B) but the serum calcium remains high and the urine calcium falls.

In 1987 the first baby was described in whom neonatal hyperparathyroidism remitted spontaneously and the infant thrived without surgical intervention. ${ }^{2}$ The father had familial hypocalciuric hypercalcaemia as in our patient and the serum calcium was only moderately raised at $2.75 \mathrm{mmol} / 1$. The PTH was five times the upper limit of normal but by 7 months skeletal recovery was complete. In 1989 a baby was described who also had a bell shaped thorax and presented with respiratory distress. ${ }^{3}$ Radiographs showed marked osteopenia and there was hepatomegaly. The hepatomegaly is thought to be due to the abnormal shape of the chest wall, which displaces the diaphragm and the liver downwards. This baby recovered spontaneously and by 3.5 months bone mineralisation was described radiologically as normal. Investigation of seven family members failed to reveal anyone with familial hypocalciuric hypercalcaemia; this boy could have been a new mutation.

We have described the first documented case of this condition occurring in the UK. The differential diagnosis of the hypercalcaemia is crucial to management and can only be confirmed by undertaking family 
studies. Since 1987 two other cases have been described in the world literature where the mode of presentation was as severe neonatal hyperparathyroidism with metabolic bone disease and muscle hypotonia, and over a three to seven month period the babies thrived without surgical intervention. ${ }^{2}{ }^{3}$ There is no indication once the diagnosis has been made, and in the absence of severe biochemical abnormality or severe respiratory insufficiency with gross osteopenia, for surgical removal of one or all of the parathyroid glands as in these cases the condition remits spontaneously and the baby can be managed medically.

We should like to thank Mr N Dudley, consultant surgeon, John Radcliffe Hospital, Oxford, for help with the clinical care of the patient and Borders Health Authority for investigating the patient's family.

1 Marx SJ, Attie M, Spiegel AM, et al. An association between neonatal severe primary hyperparathyroidism and familial hypocalciuric hypercalcaemia in three kindreds. $N$ Engl $f$ Mypocalciuric hypercalca $1982 ; 306: 257-64$

2 Page Lyman A, Haddow James E. Self limited neonatal hyperparathyroidism in familial hypocalciuric hypercalcaemia. F Pediatr 1987; 111: 261-4.

3 Harris Sally S, D'Ercole AJ. Neonatal hyperparathyroidism: the natural course in the absence of surgical intervention. Pediatrics 1989; 86: 421-7.

4 Foley T, Harrison H, Arnaud C, Harrison H. Familial benign hypercalcaemia. F Pediatr 1972, 81: 1060-7.

5 Marx SJ. Familial hypocalciuric hypercalcaemia. In: Heath D, Marx SJ, eds. Clinical Endocrinology. Vol 2. Calcium disorders. London: Butterworth Scientific, 1982: 217-32. 6 Gisorders. London: Butterworth Scientific, 1982: 217-32. calcium total calcium and parathyroid hormone concentrations in the diagnosis of primary hyperparathyroidism and familial benign hypercalcaemia. Ann Clin Biochem 1992; 29: $52-8$. 